\title{
A retrospective study of weight-loss predictors following bariatric surgery in Malaysian patients with obesity
}

\section{Fatin Hanani Mazri ${ }^{1}$, Suzana Shahar ${ }^{*}$, Nik Ritza Kosai ${ }^{2}$, Mohd Azahadi Omar ${ }^{3}$, Nilsiswati Ramilis ${ }^{4}$ \& Reynu Rajan ${ }^{2}$}

${ }^{1}$ Dietetics Programme, Faculty of Health Sciences, Universiti Kebangsaan Malaysia, Kuala Lumpur, Malaysia; ${ }^{2}$ Department of Surgery, Faculty of Medicine, Universiti Kebangsaan Malaysia Medical Centre, Kuala Lumpur, Malaysia; ${ }^{3}$ Institute of Public Health, Ministry of Health, Kuala Lumpur, Malaysia; ${ }^{4}$ Department of Dietetics and Food Services, Universiti Kebangsaan Malaysia Medical Centre, Kuala Lumpur, Malaysia

\begin{abstract}
Introduction: A retrospective study was conducted with the aim of determining the factors that affect weight loss among post-bariatric surgery patients. Methods: A successful weight loss outcome in this study was defined as achieving at least 50\% excess weight loss (EWL). Eligible participants were those who had undergone bariatric surgery at least two years prior to the study. Adherence to lifestyle recommendations post-bariatric surgery, binge eating, depression, and social support were assessed. Results: A total of 51 post-bariatric surgery patients were recruited with a mean post-operative period of $3.2 \pm 0.7$ years. The mean preoperative weight of $116.6 \pm 28.8 \mathrm{~kg}$ and body mass index (BMI) $45.2 \pm 8.8 \mathrm{~kg} / \mathrm{m}^{2}$ were significantly reduced to $86.6 \pm 21.0 \mathrm{~kg}$ and $33.6 \pm 6.7 \mathrm{~kg} / \mathrm{m}^{2}$, respectively, during follow-up $(p<0.001)$. A total of $66.7 \%$ of participants achieved successful weight loss following bariatric surgery, with a mean EWL of $73.6 \pm 21.9 \%$ and total weight loss (TWL) of $29.4 \pm 8.7 \%$. According to multivariate regression analysis adjusted for age and gender, pre-operative weight $(\beta=-1.580, p<0.05)$ and BMI $(\beta=-1.398$, $p<0.05)$, rate of weight loss $(\beta=1.045, p<0.01)$, and adherence to eating behaviour recommendations $(\beta=0.177, p<0.05)$ were significant predictors of weight loss outcomes post-bariatric surgery. Conclusion: The lower pre-operative weight and BMI, the faster rate of weight loss and higher adherence towards eating behaviour advice were potential predictors of greater EWL and thus could increase the chance of successful weight loss maintenance post-bariatric surgery.
\end{abstract}

Keywords: Obesity, bariatric surgery, pre-operative weight, dietary adherence, rate of weight loss

\section{INTRODUCTION}

Obesity and increases in fat accumulation, including visceral adiposity, especially in the upper body, is linked to the risk of developing type II diabetes mellitus (T2DM), cardiovascular disease, and metabolic syndrome (Eckel et al., 2011). Bariatric surgery is

\footnotetext{
*Corresponding author: Prof. Dr. Suzana Shahar

Dietetic Programme, Faculty of Health Sciences, Universiti Kebangsaan Malaysia

Jalan Raja Muda Abdul Aziz, 50300 Kuala Lumpur, Malaysia.

Telephone no.: +603-9289 7651; Email: suzana.shahar@ukm.edu.my

doi: https://doi.org/10.31246/mjn-2018-0115
} 
considered to be one of the recommended treatments for morbid obesity because it effectively promotes durable weight loss in most patients with obesity for the first 18 months post-surgery (Concors et al., 2016). Nevertheless, regaining lost weight after 2 to 10 years post-bariatric surgery is common (McGrice \& Don Paul, 2015).

Bariatric surgery only accounts for half of requirements for patient with morbid obesity to lose weight. The other half comes from behavioural modification, dietary recommendations, and exercise with psychological support to maximise the surgery's benefits (Liu, 2016). Participants who adhered to the dietary recommendations and grazed no more than once a day showed the highest weight loss (Robinson et al., 2014). Further reduction in body weight post-bariatric surgery requires support from peer, dietetic, and psychological groups (Sharman et al., 2017).

A recent study found that preoperative weight significantly predicted weight loss (Vanoh, Shahar \& Nik Kosai, 2015). However, psychosocial variables were not associated with the rate of weight loss in that study and other studies of one-year post-bariatric surgery patients (Fox et al., 2015). Adherence to dietary recommendations was not associated with weight loss during a short-term assessment of successful post-bariatric surgeries (Sherf-Dagan et al., 2017). There is thus a need to investigate the medium-term success of weight loss post-bariatric surgery, with special emphasis on dietary adherence and psychosocial variables. Thus, the present study aimed to determine the pre-operative, dietary, lifestyle, and psychosocial factors that affect weight loss in the medium-term follow-up.

\section{MATERIALS AND METHODS}

\section{Study design and sampling}

This was a retrospective study of postbariatric surgery patients from the
Obesity Clinic, University Kebangsaan Malaysia Medical Centre (UKMMC). Data collection was undertaken from September until December 2016. The list of patients who underwent bariatric surgery from January 2012 to December 2014 was obtained from the Surgical Department of UKMMC. Participants were recruited via convenience sampling. The inclusion criteria were patients $\geq 18$ years of age and they had to be at least 2 years after bariatric surgery had been performed. The exclusion criteria were pregnancy, severe mental illness, mental disabilities, deafness, and patients undergoing revision surgery during the period of study. Initially, patients were invited to participate in this study by the researchers through phone calls. A self-reported questionnaire was sent to patients who agreed to participate via post and email. Depending on the preference of the participants, reminders were sent through phone messages and email, requesting that they complete their questionnaire. Meanwhile, patients who attended the Obesity Outpatient Clinic of UKMMC for follow-up were directly invited to participate in this research. Out of 123 patients who were identified as prospective participants, 68 responded to the invitation and agreed to participate. However, only 51 patients were recruited as participants because some were excluded due to incomplete questionnaires $(n=3)$, failure to return the questionnaires $(n=10)$ or because they withdrew $(n=4)$ from the study. Informed consent was obtained from all participants. This study received ethical approval (NN-2016-048) from the Research and Ethical Committee of Medical Research of Universiti Kebangsaan Malaysia.

\section{Outcome measures}

Self-reported weight were used for the participants who were recruited through phone calls, while the height measurement were obtained from medical records. There was a significant 
correlation between measured and reported weight and height (Ivezaj \& Grilo, 2017). Whereas, the height and weight were measured for participants who were recruited at the Obesity Clinic. The current weight was used to calculate the post-operative body mass index (BMI) as well as the excess weight loss (EWL) and total weight loss (TWL) percentages (Ivezaj \& Grilo, 2017). The EWL percentage was calculated using the formula described by Deitel, Gawdat $\&$ Melissas (2007): EWL \% $=100 \times$ (preoperative weight - current body weight)/ (pre-operative weight - ideal body weight at BMI $25 \mathrm{~kg} / \mathrm{m} 2$ ) (Greenstein $\&$ Deitel, 2007). The TWL percentage was calculated as: TWL $\%=100 \times$ (preoperative weight - current body weight)/ (pre-operative weight) (Pekkarinen et al., 2016). Height, pre-operative weight, type of bariatric surgery, date of bariatric surgery, the number of follow-up visits at the Obesity Clinic, and weight history upon each follow-up (at 3, 6, 9 months, and 1 and 2-year post-surgery) were obtained from medical records. Successful weight loss maintenance among post-bariatric patients was defined as $\geq 50 \%$ EWL (Fox et al., 2015).

\section{Materials}

The Bariatric Surgery Self-Management Questionnaire (BSSQ) was used to measure perceived adherence of participants to the lifestyle recommendations for post-bariatric surgery (Welch et al., 2008). The questionnaire was translated into Bahasa Malaysia (Malay language) using backto-back translation with a Cronbach's alpha of 0.85 . This questionnaire was in the Likert scale format with choices of "never", "sometimes", "mostly", and "always". The total score was converted into a 0 to 100 range. A higher score indicated a higher adherence of participants to the recommendations.

The Binge Eating Scale (BES) was used to assess binge eating behaviour in participants (Gormally et al., 1982). The validated Bahasa Malaysia version of the BES, with a Cronbach's alpha of 0.89 , was used in this study (Robert et al., 2013). In addition, the Beck Depression Inventory (BDI) was used to measure the presence and degree of depression (Beck, Steer \& Brown, 1996). The Bahasa Malaysia version was adopted from Vanoh et al. (2015) with a Cronbach's alpha of 0.93 .

The Duke Social Support and Stress Scale (DUSOCS) (Parkerson, Broadhead $\&$ Tse, 1991) was used to measure the support and stress from the social environment of the participants. In this study, only the social support part of the questionnaire was utilised. The questionnaire consisted of two domains: social support from family members (including both blood related and nonblood related) and non-family members, such as neighbours, colleagues, and friends. The Bahasa Malaysia translation of DUSOCS from Hudin et al. (2017) was adopted with Cronbach's alpha of 0.53 for the family domain and 0.70 for the non-family domain.

\section{Statistical analysis}

The categorical data are presented as the frequency and percentage, while for continuous data, the mean and standard deviation (SD) are reported. Survival analysis (time-to-event) was used because each recruited participant had a different post-operative period and this study also included participants who did not achieve a successful weight loss outcome post-operatively (censored data). The log rank test was used to compare survival between different groups. Univariate and multivariate regressions were employed to determine the factors that affected weight loss postbariatric surgery. Statistical analysis was performed using SPSS version 22 (IBM Corp., Armonk, NY). The statistical significant was set at $p<0.05$. 


\section{RESULTS}

As shown in Table 1, the age of the participants ranged from 20 to 60 years old, with a mean of $45.5 \pm 8.9$ years. The majority of participants were women (68.6\%), Malays (84.3\%), and married $(72.5 \%)$. The mean post-operative period was $3.2 \pm 0.7$ years, ranging from 2.1 to 4.8 years (25.3 to 58.7 months). A total of 41 participants underwent sleeve gastrectomy-bariatric surgery (80.4\%), nine participants received Roux-en-Y gastric bypass (RYGB) (17.6\%) and one participant underwent laparoscopic adjustable gastric banding (LAGB) (2.0\%).

Participants ( $\mathrm{n}=34,66.7 \%)$ who successfully maintained their weight loss ( $\geq 50 \%$ EWL) lost significantly higher percent EWL $(73.6 \pm 21.9 \%$ vs $35.7 \pm 9.4 \%$, $p<0.001)$ and TWL $(29.4 \pm 8.7 \%$ vs $16.1 \pm 4.7 \%, \quad p<0.001)$ compared with participants $(\mathrm{n}=17, \quad 33.3 \%)$ who experienced sub-optimal weight loss
$(<50 \%$ EWL) (data not shown). Table 2 shows that there were no significant differences observed in post-operative weight and BMI and the EWL and TWL percentages when participants were grouped into their respective postoperative years (from year 2 to year 4). Nonetheless, the mean rate of weight loss was the highest in participants at 2 years post-bariatric surgery $(1.2 \pm 0.7 \mathrm{~kg} /$ month) compared with those at 3 years $(0.7 \pm 0.3 \mathrm{~kg} / \mathrm{month})$ and 4 years $(0.5 \pm 0.2$ $\mathrm{kg} /$ month $) \quad(p<0.05) \quad$ post-bariatric surgery. Figure 1 shows the difference in rate of weight loss between the successful weight loss maintainers and the sub-optimal weight loss group. There were no significant differences observed during the first 3 months post-bariatric surgery between the group. However, a significant difference was observed from 6 months onwards. Kaplan-Meier analysis was used to quantify the timeframe over which participants achieved at least a 50\% EWL. According to the

Table 1. Demographic data of participants

\begin{tabular}{|c|c|c|c|c|}
\hline Variable & $\begin{array}{l}\text { Total } \\
(N=51)\end{array}$ & $\begin{array}{c}\text { Men } \\
(n=16)\end{array}$ & $\begin{array}{l}\text { Women } \\
(n=35)\end{array}$ & p-value \\
\hline Age $^{\dagger}$ (years), mean $\pm S D$ & $\begin{array}{c}45.5 \pm 8.9 \\
\text { (range: } 20-60 \text { ) }\end{array}$ & $44.5 \pm 10.5$ & $45.6 \pm 8.2$ & 0.686 \\
\hline \multicolumn{5}{|l|}{ Gender ${ }^{\ddagger}, n(\%)$} \\
\hline Men & $16(31.4)$ & & & \\
\hline Women & $35(68.6)$ & & & \\
\hline Ethnicity ${ }^{\ddagger}, n(\%)$ & & & & 0.240 \\
\hline Malay & $43(84.3)$ & $12(75.0)$ & $31(88.6)$ & \\
\hline Chinese & $1(2.0)$ & $1(6.25)$ & - & \\
\hline Indian & $5(9.8)$ & $2(12.5)$ & $3(8.6)$ & \\
\hline Others & $2(3.9)$ & $1(6.25)$ & $1(2.8)$ & \\
\hline Marital status ${ }^{\ddagger}, n(\%)$ & & & & 0.322 \\
\hline Single & 9 (17.6) & $4(25)$ & $5(14.3)$ & \\
\hline Married & $37(72.5)$ & $10(62.5)$ & $27(77.2)$ & \\
\hline Divorcee/widow/widower & $5(9.8)$ & $2(12.5)$ & $3(8.5)$ & \\
\hline Post-operative period $^{\dagger}$ (years), mean $\pm S D$ & $\begin{array}{c}3.2 \pm 0.7 \\
\text { (range: } 2.1-4.8 \text { ) }\end{array}$ & $3.4 \pm 0.6$ & $3.2 \pm 0.7$ & 0.416 \\
\hline \multicolumn{5}{|l|}{ Type of surgery, $n(\%)$} \\
\hline Sleeve gastrectomy & $41(80.4)$ & $12(75.0)$ & $29(82.9)$ & \\
\hline Roux-en Y gastric bypass & $9(17.6)$ & $4(25.0)$ & $5(14.3)$ & \\
\hline Adjustable gastric banding & $1(2.0)$ & 0 & $1(100)$ & \\
\hline
\end{tabular}

†using independent t-test; " using Chi-square test 
Table 2. Anthropometric data at various time intervals following surgery

\begin{tabular}{lccc}
\hline Variables & $\begin{array}{c}2 \text { years } \\
(n=18)\end{array}$ & $\begin{array}{c}3 \text { years } \\
(n=22)\end{array}$ & $\begin{array}{c}4 \text { years } \\
(n=11)\end{array}$ \\
\hline Pre-operative weight $(\mathrm{kg})$, mean $\pm S D$ & $121.6 \pm 32.9$ & $116.4 \pm 28.4$ & $108.7 \pm 22.9$ \\
Post-operative weight $(\mathrm{kg})$, mean $\pm S D$ & $83.3 \pm 19.4$ & $89.9 \pm 21.9$ & $85.2 \pm 22.6$ \\
Pre-operative BMI $\left(\mathrm{kg} / \mathrm{m}^{2}\right)$, mean $\pm S D$ & $46.6 \pm 11.5$ & $45.2 \pm 7.5$ & $42.7 \pm 6.0$ \\
Post-operative BMI $\left(\mathrm{kg} / \mathrm{m}^{2}\right)$, mean $\pm S D$ & $31.9 \pm 6.6$ & $35.1 \pm 6.9$ & $33.4 \pm 6.4$ \\
$\%$ EWL, mean $\pm S D$ & $72.2 \pm 26.6$ & $53.6 \pm 24.8$ & $57.3 \pm 22.2$ \\
$\%$ TWL, mean $\pm S D$ & $29.9 \pm 11.5$ & $22.3 \pm 8.1$ & $22.1 \pm 7.0$ \\
Rate of weight loss $(\mathrm{kg} / \mathrm{month})$, mean $\pm S D$ & $1.2 \pm 0.7^{*}$ & $0.7 \pm 0.3^{*}$ & $0.5 \pm 0.2^{* *}$ \\
Proportion with $\geq 50 \% \mathrm{EWL}, n(\%)$ & $14(77.8)$ & $11(50.0)$ & $8(72.7)$ \\
\hline
\end{tabular}

${ }^{*} p$-value $<0.05 ;{ }^{* *} p$ value $<0.001$ statistically significant using ANOVA test

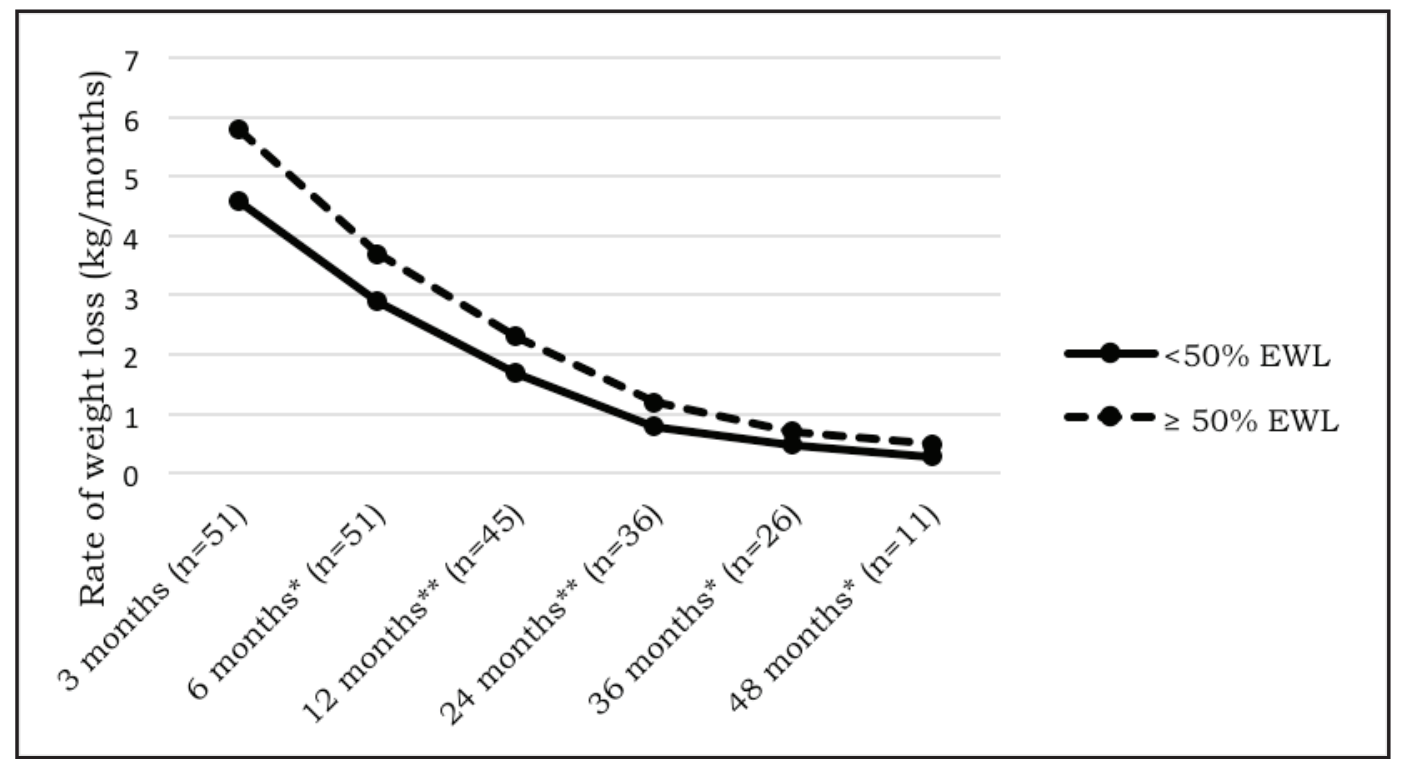

Figure 1. Rate of weight loss between $\geq 50 \% \mathrm{EWL}$ and $<50 \% \mathrm{EWL}$ ${ }^{*} p$-value $<0.05,{ }^{* *} p$ value $<0.01$ significant in independent $\mathrm{t}$-test

result of the Kaplan-Meier analysis, the overall median of time for participants in this study to achieve a 50\% EWL was 12 months (95\% CI: 7.8 to 16.2 months).

Participants who successfully maintained their weight loss perceived better adherence to eating behaviour and water intake recommendations and engaged in more physical activity. However, participants who did not achieve a $50 \%$ EWL in this mid-term follow-up perceived better adherence towards protein, fruits, vegetables, and vitamin intake recommendations, received more support, and had a lower level of depression and binge eating score compared with the successful group (Table 3). There were no significant differences observed in regard to the BSSQ score, binge eating episodes, depression, and support obtained between participants who achieved a 50\% EWL and those who did not. All of the predictors for mid-term weight loss post-bariatric surgery were tested via univariate regression analysis 
Table 3. BSSQ components and psychosocial profile of participants

\begin{tabular}{|c|c|c|c|c|c|}
\hline Variables & $\begin{array}{l}\text { Total } \\
(N=51)\end{array}$ & $\begin{array}{c}<50 \% E W L \\
(n=18)\end{array}$ & $\begin{array}{c}\geq 50 \% \text { EWL } \\
(n=33)\end{array}$ & p-value & $95 \% C I$ \\
\hline $\begin{array}{l}\text { Bariatric Surgery Self- } \\
\text { Management Questionnaire } \\
(\mathrm{BSSQ})^{\dagger}, \% \pm S D\end{array}$ & $56.2 \pm 15.3$ & $56.9 \pm 17.1$ & $55.9 \pm 14.4$ & 0.836 & $-8.1,10.0$ \\
\hline BSSQ - Eating Behaviour ${ }^{\dagger}$ & $67.9 \pm 20.1$ & $64.8 \pm 18.2$ & $69.7 \pm 21.1$ & 0.413 & $-16.8,7.0$ \\
\hline BSSQ - Protein ${ }^{\dagger}$ & $63.1 \pm 21.0$ & $64.4 \pm 21.1$ & $62.4 \pm 21.3$ & 0.752 & $-10.5,14.5$ \\
\hline BSSQ - Water Intake ${ }^{\dagger}$ & $50.7 \pm 21.3$ & $50.3 \pm 21.7$ & $50.8 \pm 21.4$ & 0.933 & $-13.2,12.1$ \\
\hline $\begin{array}{l}\text { BSSQ - Fruit, Veggie, } \\
\text { Whole grain }^{\dagger}\end{array}$ & $52.7 \pm 20.8$ & $58.6 \pm 25.7$ & $49.5 \pm 17.1$ & 0.189 & $-4.8,23.1$ \\
\hline BBSQ - Physical Activity ${ }^{\dagger}$ & $44.4 \pm 23.7$ & $42.6 \pm 29.3$ & $45.5 \pm 20.5$ & 0.685 & $-16.9,11.2$ \\
\hline BSSQ - Vitamin Intake ${ }^{\dagger}$ & $49.7 \pm 34.2$ & $57.4 \pm 31.9$ & $45.5 \pm 35.2$ & 0.237 & $-8.1,32.0$ \\
\hline Binge Eating Scale ${ }^{\dagger}$, mean $\pm S D$ & $8.4 \pm 6.9$ & $7.7 \pm 4.6$ & $8.8 \pm 7.9$ & 0.586 & $-5.2,3.0$ \\
\hline $\begin{array}{l}\text { BECK Depression Inventory }{ }^{\dagger} \text {, } \\
\text { mean } \pm S D\end{array}$ & $9.5 \pm 11.5$ & $8.8 \pm 11.4$ & $9.8 \pm 11.7$ & 0.780 & $-7.8,5.9$ \\
\hline $\begin{array}{l}\text { DUSOCS Social Support }{ }^{\dagger}, \\
\text { mean } \pm S D\end{array}$ & $39.9 \pm 24.7$ & $45.5 \pm 27.3$ & $36.9 \pm 23.1$ & 0.243 & $-6.0,23.0$ \\
\hline $\begin{array}{l}\text { DUSOCS Family Support }{ }^{\ddagger}, \\
\text { mean } \pm S D\end{array}$ & $40.9 \pm 27.3$ & $47.2 \pm 27.5$ & $37.4 \pm 27.0$ & 0.225 & $-6.2,25.8$ \\
\hline No support, $n(\%)$ & $5(9.8)$ & $2(11.1)$ & $3(9.1)$ & & \\
\hline Low support, $n(\%)$ & 27 (52.9) & $8(44.4)$ & 19 (57.6) & & \\
\hline Moderate support, $n(\%)$ & 9 (17.6) & $4(22.2)$ & $5(15.2)$ & & \\
\hline High support, $n(\%)$ & $10(19.6)$ & $4(22.2)$ & $6(18.2)$ & & \\
\hline $\begin{array}{l}\text { DUSOCS Non-Family } \\
\text { Support }^{\ddagger}, \text { mean } \pm S D\end{array}$ & $30.6 \pm 22.9$ & $33.9 \pm 28.9$ & $28.8 \pm 19.1$ & 0.508 & $-10.5,20.7$ \\
\hline No support, $n(\%)$ & $6(11.8)$ & $2(11.1)$ & $4(12.1)$ & & \\
\hline Low support, $n(\%)$ & $24(47.1)$ & $8(44.4)$ & $16(48.5)$ & & \\
\hline Moderate support, $n(\%)$ & $10(19.6)$ & $3(16.7)$ & $7(21.2)$ & & \\
\hline High support, $n(\%)$ & $11(21.6)$ & $5(27.8)$ & $6(18.2)$ & & \\
\hline
\end{tabular}

${ }^{\dagger}$ using independent t-test; ${ }^{\ddagger}$ using Chi-square test

(Table 4) prior to multivariate analysis. Only the pre-operative BMI, percentage of pre-operative excess weight, and rate of weight loss were significant predictors $(p<0.05)$ in this univariate analysis. However, the post-operative period, pre-operative weight, and BSSQeating behaviour were also included in the multivariate analysis because their $p$ values almost reached significance at $p<0.05$. A $p$-value of 0.2 has been suggested for use in small sample sized studies (Sipsma et al., 2011).

The multivariate model (Table 5), adjusted for age and gender, explained $78.8 \%$ of the variance to achieve a higher
EWL post-bariatric surgery $\left(\mathrm{R}^{2}=0.788\right.$, $\mathrm{F}(8)=19.52, p<0.001)$. This result showed that pre-operative weight $(p=0.030)$ and BMI $(p=0.037)$, adherence to eating behaviour recommendations (BSSQeating behaviour) $(p=0.025)$, and rate of weight loss $(p<0.001)$ were significant predictors of EWL post-bariatric surgery (Table 4). The lower pre-operative weight of -1.580 (95\% CI: $-2.69,-0.14)$ and BMI of -1.398 (95\% CI: $-7.95,-0.27)$, greater rate of weight loss of 1.045 (95\% CI: $37.35,60.46)$ and adherence to eating behaviour recommendations of 0.177 (95\% CI: 0.03, 0.43) predicted greater EWL post-bariatric surgery. 
Table 4. Univariate regression between the predictors and percentage of excess weight loss following bariatric surgery

\begin{tabular}{lcccc}
\hline Variable & $\beta$ & $S E$ & $p$-value & OR $(95 \%$ CI $)$ \\
\hline Age & -0.430 & 0.41 & 0.301 & $-0.148(-1.26,0.40)$ \\
Gender & -5.550 & 7.85 & 0.483 & $-0.101(-21.32,10.22)$ \\
Post-operative period & -0.819 & 0.43 & $0.061^{\dagger}$ & $-0.264(-1.68,0.04)$ \\
Pre-operative weight & -0.215 & 0.12 & $0.089^{\dagger}$ & $-0.241(-0.47,0.03)$ \\
Preoperative BMI & -0.987 & 0.40 & $0.016^{*}$ & $-0.336(-1.78,-0.19)$ \\
\% Excess weight pre-operative & -0.302 & 0.14 & $0.039^{*}$ & $-0.290(-0.59,-0.16)$ \\
Rate of weight loss & 19.773 & 6.06 & $0.002^{*}$ & $0.423(7.60,31.94)$ \\
Total BECK & -0.306 & 0.32 & 0.343 & $-0.135(-0.95,0.34)$ \\
Total BES & -0.656 & 0.52 & 0.217 & $-0.176(-1.71,0.40)$ \\
Total BSSQ & 0.343 & 0.40 & 0.396 & $0.121(-0.46,1.15)$ \\
$\quad$ BSSQ - Protein & 0.230 & 0.17 & 0.190 & $0.187(-0.12,0.58)$ \\
$\quad$ BSSQ - Eating behaviour & 0.333 & 0.18 & $0.067^{\dagger}$ & $0.258(-0.02,0.69)$ \\
$\quad$ BSSQ - Water intake & -0.065 & 0.17 & 0.711 & $-0.053(-0.41,0.28)$ \\
$\quad$ BSSQ - Physical activity & 0.158 & 0.15 & 0.310 & $0.145(-0.15,0.47)$ \\
BSSQ - Vitamin intake & -0.006 & 0.11 & 0.956 & $-0.008(-0.22,0.21)$ \\
$\quad$ BSSQ - Fruit, vegetables, whole grain & 0.016 & 0.18 & 0.927 & $0.013(-0.34,0.37)$ \\
Total support & -0.128 & 0.15 & 0.391 & $-0.123(-0.43,0.17)$ \\
Family support & -0.152 & 0.13 & 0.261 & $-0.160(-0.42,0.12)$ \\
Non-family support & -0.027 & 0.16 & 0.867 & $-0.024(-0.35,0.30)$ \\
\hline
\end{tabular}

" $p$ value $<0.05$, significant in univariate regression analysis

${ }^{\dagger}$ were included in multivariate regression analysis

Table 5. Multivariate regression between the predictors and percentage of excess weight loss following bariatric surgery

\begin{tabular}{lcccc}
\hline Variable & $\beta$ & $S E$ & $p$ value & OR $(95 \%$ CI $)$ \\
\hline Post-operative period & 0.503 & 0.30 & 0.097 & $0.162(-0.09,1.10)$ \\
Pre-operative weight & -1.415 & 0.63 & $0.030^{*}$ & $-1.580(-2.69,-0.14)$ \\
Pre-operative BMI & -4.105 & 1.90 & $0.037^{*}$ & $-1.398(-7.95,-0.27)$ \\
\% Excess weight pre-operative & 1.918 & 1.27 & 0.139 & $1.845(-0.65,4.48)$ \\
Rate of weight loss & 48.905 & 5.73 & $<0.001^{* *}$ & $1.045(37.35,60.46)$ \\
BSSQ - Eating behaviour & 0.228 & 0.10 & $0.025^{*}$ & $0.177(0.03,0.43)$ \\
\hline
\end{tabular}

" $p$-value $<0.05$ and ${ }^{* *} p$ value $<0.001$ significant in multivariate regression analysis

${ }^{\dagger} \mathrm{p}$-value by multiple linear regression adjusted to age and gender

$S E$, standard error; $C I$, confidence interval

\section{DISCUSSION}

As with other studies (Alexandrou et al., 2015; Himpens, Dobbeleir \& Peeters, 2010), ours also found that the EWL percentage decreased as the postoperative years increased. The highest mean EWL percentage was observed among participants who were in their second post-operative year. In addition, the output from the Kaplan-Meier analysis showed that the minimum time for participants to achieve a $50 \%$ EWL was approximately 8 months. The current study also discovered that the difference in the rate of weight loss between the successful and the 
unsuccessful weight loss maintainers groups was only observed to start from 6 months after the surgery. Drastic weight loss begins immediately following bariatric surgery and continues for 6 to 12 months (which is also known as the post-operative honeymoon period). The initial weight loss occurs without any effort from the patient due to the forced reduction of food intake because the stomach size has been reduced, and also due to the side effects of surgery, such as vomiting and food intolerance (Lynch, 2016). Subsequently, weight stabilisation and the inactive weight loss period begin 18 to 24 months postbariatric surgery (Jones, Cleator \& Yorke, 2016). Hence, the current study was conducted among post-bariatric patients who had undergone surgery at least 2 years ago.

The pre-operative weight, BMI, rate of weight loss and adherence to eating behaviour recommendations were significant predictors of greater EWL after bariatric surgery when adjusted for age and gender. The pre-operative weight had the greatest significant influence on predicting successful weight loss in the multivariate model as reduction in $1 \mathrm{~kg}$ of pre-operative weight will increase EWL by $1.6 \%$. Our findings on pre-operative weight and BMI as predictors of successful weight loss are aligned with those of previous studies (Fox et al., 2015; Obeidat \& Shanti, 2016; Steinbeisser, McCracken $\&$ Kharbutli, 2017). The impact of preoperative weight on enhancing weight loss after surgery remains controversial and is believed to be multifactorial (Steinbeisser et al., 2017). Patients who successfully lost weight during the preoperative period might have had more motivation to follow the dietary and lifestyle recommendations and thus be more likely to achieve successful weight loss and maintain it (Gerber et al., 2016). Furthermore, a greater pre-operative weight reduction was associated with a reduced liver size, which could then reduce the risk of complications during surgery by reducing the risk of intraoperative bleeding from liver injury (van Wissen et al., 2016). Therefore, improvements in pre-operative weight loss regimens are needed to promote successful post-operative weight loss. Further study is needed to analyse the contribution of pre-operative weight to post-operative weight loss.

In this study, the higher rate of weight loss also predicted greater EWL post-bariatric surgery. The rate of weight loss decreased as the time after surgery increased. This reduction might be related to reduction in the compliance of patients to dietary recommendations (Finkler, Heymsfield \& St-Onge, 2012). Moreover, early post-operative weight loss significantly predicted greater weight loss at 2 years after bariatric surgery (Obeidat \& Shanti, 2016). Postbariatric surgery care requires patients to make significant lifestyle changes that involve their eating behaviour and physical activity (Liu, 2016). Dietary recommendations for the period following bariatric surgery are designed to aid patients in achieving maximal weight loss and in reducing the risk of postsurgical complications. Thus, dietary adherence is one of the most important factors for the long-term success of bariatric surgery (McGrice \& Don Paul, 2015). The lack of adherence to nutritional guidelines is associated with insufficient weight loss post-operatively, while self-reported adherence to the post-operative diet at week 20 was associated with increased weight loss at post-operative week 92 (Junior, do Amaral \& Nonino-Borges, 2011). The current study's findings regarding the importance of adherence to eating behaviour recommendations reflects the crucial role of dietitians in managing the nutrition of bariatric surgery patients during both the pre- and post-operative periods (Sharman et al., 2017). Patients need to go through pre-operative weight loss regimens and maintain their weight 
loss by modifying their previous dietary and lifestyle practices. Hence, to sustain the dietary and lifestyle modifications, long-term dietetic care is required (Jastrzębska-Mierzyńska et al., 2015).

A limitation of this study was that most of the latest weight data were self-reported. Only the perceived adherence of participants to the dietary recommendations was reported, and their dietary intake was not measured. As such, a comparison between perceived adherence of participants with their actual practice could not be made. In addition, a successful postbariatric surgery outcome should not solely focus on weight loss but should also include the improvement of the comorbidity status. However, this current study does not report on the status of co-morbidities.

\section{CONCLUSION}

The success of weight loss after bariatric surgery was reflected by the percent EWL. The current study demonstrated that lower pre-operative weight, BMI, higher rate of pre-operative weight loss and adherence to eating behaviour recommendations could significantly result in a greater percent EWL, when adjusted for age and gender. The postoperative information in this paper provides useful insights for healthcare professionals to potentially improve patient care and maximise the benefits of bariatric surgery for each patient.

\section{Acknowledgements}

The authors would like to thank the staff at Obesity Outpatients Clinic, UKMMC and all the participants involved in this study. This study was funded by Research University grant DPP 2015.

\section{Authors' contributions}

FHM, conducted the study, data analysis, prepared the draft of the manuscript and reviewed it; SS, principal investigator, conceptualised the study and reviewed manuscript; NRK, led the data collection at UKMMC and reviewed the manuscript; MAO, assisted in data analysis and interpretation and reviewed the manuscript; NR, advised on methodology, assisted in data collection and reviewed the manuscript; RR, assisted in data interpretation and reviewed the manuscript.

\section{Conflict of interest}

The authors declared that they had no conflict of interest.

\section{Non-standard abbreviations used}

BDI, Beck Depression Inventory; BES, Binge Eating Scale; BMI, body mass index; BSSQ, Bariatric Surgery Self-Management Questionnaire; DUSOCS, Duke Social Support and Stress Scale; EWL, excess weight loss; TWL, total weight loss; UKMMC, Universiti Kebangsaan Malaysia Medical Centre.

\section{References}

Alexandrou A, Athanasiou A, Michalinos A, Felekouras E, Tsigris C \& Diamantis T (2015). Laparoscopic sleeve gastrectomy for morbid obesity: 5-year results. Am J Surg 209(2):230234. doi:10.1016/j.amjsurg.2014.04.006

Beck AT, Steer RA \& Brown GK (1996). In: BDIII, Beck depression inventory: manual. From http: / / www.worldcat.org/title/bdi-ii-beckdepression-inventory-manual/oclc/36075838. [Retrieved February 12 2016].

Concors SJ, Ecker BL, Maduka R, Furukawa A, Raper SE, Dempsey DD, Williams NN \& Dumon KR (2016). Complications and surveillance after bariatric surgery. Curr Treat Options Neurol 18(1):5. doi:10.1007/s11940-015-0383-0

Deitel M, Gawdat K \& Melissas J (2007). Reporting weight loss 2007. Obes Surg 17(5):565-568. doi:10.1007/s11695-007-9116-0

Eckel RH, Kahn SE, Ferrannini E, Goldfine AB, Nathan DM, Schwartz MW, Smith RJ \& Smith SR (2011). Obesity and type 2 diabetes: what can be unified and what needs to be individualized? Diabetes Care 34(6):14241430. doi: $10.2337 /$ dc11-0447

Finkler E, Heymsfield SB \& St-Onge MP (2012). Rate of weight loss can be predicted by patient characteristics and intervention strategies. $J$ Acad Nutr Diet 112(1):75-80. doi:10.1016/j. jada.2011.08.034

Fox B, Chen E, Suzo A, Jolles S, Greenberg JA, Campos GM, Voils CI \& Funk LM (2015). Dietary and psych predictors of weight loss after gastric bypass. J Surg Res 197(2):283290. doi:10.1016/j.jss.2015.04.019 
Gerber P, Anderin C, Gustafsson UO \& Thorell A (2016). Weight loss before gastric bypass and postoperative weight change: data from the Scandinavian Obesity Registry (SOReg). Surg Obes Relat Dis 12(3):556-562. doi:10.1016/j. soard.2015.08.519

Gormally J, Black S, Daston S \& Rardin D (1982). The assessment of binge-eating severity among obese persons. Addict Behav 7(1):47-55. doi:10.1016/0306-4603(82)90024-7

Greenstein R \& Deitel M (2007). Reporting weight loss. Obes Surg 17(9):1275-1276. doi:10.1007/ s11695-007-9218-8

Himpens J, Dobbeleir J \& Peeters G (2010). Longterm results of laparoscopic sleeve gastrectomy for obesity. Ann Surg 252(2):319-324. doi:10.1097/SLA.0b013e3181e90b31

Hudin R, Shahar S, Ibrahim N \& Yahaya H (2017). Influence of socio-economic and psychosocial factors on food insecurity and nutritional status of older adults in FELDA settlement in Malaysia. $J$ Clin Gerontol 8(1):35-40 doi:10.24816/jcgg.2017.v8i1.06

Ivezaj V \& Grilo CM (2017). Accuracy of selfreported height and weight among sleeve gastrectomy patients with disordered eating. Obes Surg 27(1):267-270. doi:10.1007/ s11695-016-2443-2

Jastrzębska-Mierzyńska M, Ostrowska L, Wasiluk D \& Konarzewska-Duchnowska E (2015). Dietetic recommendations after bariatric procedures in the light of the new guidelines regarding metabolic and bariatric surgery. Roczniki Państwowego Zakladu Higieny 66(1):13-9.

Jones L, Cleator J \& Yorke J (2016). Maintaining weight loss after bariatric surgery: when the spectator role is no longer enough. Clin Obes 6(4):249-258. doi:10.1111/cob.12152

Junior WS, do Amaral JL \& Nonino-Borges CB (2011). Factors related to weight loss up to 4 years after bariatric surgery. Obes Surg 21(11):1724-1730. doi:10.1007/s11695-0110420-3

Liu RH (2016). Do behavioral interventions delivered before bariatric surgery impact weight loss in adults? A systematic scoping review. Bariatr Surg Pract Patient Care 11(2):39-48.

Lynch A (2016). "When the honeymoon is over, the real work begins:" Gastric bypass patients' weight loss trajectories and dietary change experiences. Soc Sci Med 151:241-249. doi:10.1016/j.socscimed.2015.12.024
McGrice M \& Don Paul K (2015). Interventions to improve long-term weight loss in patients following bariatric surgery: challenges and solutions. Diabetes Metab Syndr Obes 23(8):263-274. doi:10.2147/DMSO.S57054

Obeidat F \& Shanti H (2016). Early weight loss as a predictor of 2-year weight loss and resolution of comorbidities after sleeve gastrectomy. Obes Surg 26(6):1173-1177. doi:10.1007/s11695015-1903-4

Parkerson GR, Broadhead WE \& Tse CKJ (1991). Validation of the Duke Social Support and Stress Scale. Fam Med 23(5):357-60.

Pekkarinen $\mathrm{T}$, Mustonen $\mathrm{H}$, Sane $\mathrm{T}$, Jaser $\mathrm{N}$, Juuti A \& Leivonen M (2016). Long-term effect of gastric bypass and sleeve gastrectomy on severe obesity: do preoperative weight loss and binge eating behavior predict the outcome of bariatric surgery? Obes Surg 26(9):2161-2167. doi:10.1007/s11695-016-2090-7

Robert SA, Rohana AG, Suehazlyn Z, Maniam T, Azhar SS \& Azmi KN (2013). The validation of the malay version of binge eating scale: a comparison with the structured clinical interview for the DSM-IV. J Eat Disord 1:28. doi:10.1186/2050-2974-1-28

Robinson AH, Adler S, Stevens HB, Darcy AM, Morton JM \& Safer DL (2014). What variables are associated with successful weight loss outcomes for bariatric surgery after 1 year? Surg Obes Relat Dis 10(4):697-704. doi:10.1016/j. soard.2014.01.030

Sharman M, Hensher M, Wilkinson S, Williams D, Palmer A, Venn A \& Ezzy D (2017). What are the support experiences and needs of patients who have received bariatric surgery? Hlth Expect 20(1):35-46. doi:10.1111/hex.12423

Sherf-Dagan S, Keidar A, Raziel A, Sakran N, Goitein D, Shibolet O \& Zelber-Sagi S (2017). Do bariatric patients follow dietary and lifestyle recommendations during the first postoperative year? Obes Surg 27(9): 22582271. doi:10.1007/s1 1695-017-2633-6

Steinbeisser M, McCracken J \& Kharbutli B (2017). Laparoscopic sleeve gastrectomy: preoperative weight loss and other factors as predictors of postoperative success. Obes Surg 27(6):15081513. doi: $10.1007 /$ s1 1695-016-2520-6

van Wissen J, Bakker N, Doodeman HJ, Jansma EP, Bonjer HJ \& Houdijk APJ (2016). Preoperative methods to reduce liver volume in bariatric surgery: a systematic review. Obes Surg 26(2):251-256. doi:10.1007/s11695-0151769-5 
Vanoh D, Shahar S \& Nik Kosai NM (2015). Association between nutrient adequacy and psychosocial factors with overall rate of weight loss after bariatric surgery. Asia Pac J Clin Nutr 24(4):610-619. doi:10.6133/ apjen.2015.24.4.11

Welch G, Wesolowski C, Piepul B, Kuhn J, Romanelli J \& Garb J (2008). Physical activity predicts weight loss following gastric bypass surgery: findings from a support group survey. Obes Surg 18(5):517-524. doi:10.1007/ s1 1695-007-9269-x 